\title{
Exploring local projects for sustainable energy in system transition: local perceptions of success
}

Beck Collins*, David Boyd, Rachel Curzon

Birmingham School of the Built Environment, Birmingham City University, Millennium Point, Curzon Street, Birmingham, B4 7XG, UK

*Corresponding Author

Email Addresses; Beck.Collins@bcu.ac.uk (Beck Collins) David.Boyd@bcu.ac.uk (David Boyd) Rachel.Curzon@bcu.ac.uk (Rachel Curzon)

\begin{abstract}
In the sustainability transitions literature, 'success' is conceived as the transition from an unsustainable system to a sustainable one. However, this view hides a more profound complexity in individual projects which can contribute to system transition. This paper focuses instead on local projects as key sites for change. In two case studies of UK sustainable energy projects, success is shown to be characterised by different causative beliefs held by different people about the problems being addressed, which predetermines solutions to those problems; and hence the nature of success. By acknowledging this multiplicity of success, as perceived by ordinary residents and project organisers as well as transition scholars, 'narratives of success' can be recognised, enabling future projects to build on success, and continue along the path to transition. This reconceptualization provides transition scholars with new ways of understanding and effecting transitions; by focusing on the project level, which is useful in contexts with varying commitment to sustainability.
\end{abstract}

Keywords; sustainability transitions; sustainable energy; success; wicked problems

\section{Introduction}

Transitions from unsustainable systems of service provision to sustainable systems are urgently required given the threat of climate change (Farla et al., 2012, IPCC, 2014). Previous research has made use of insights from the Multi-Level Perspective (MLP) to explain such transitions and to understand how to drive them (Geels, 2002, Seyfang and Longhurst, 2016). Attempts are being made to operationalize this understanding in programmes to effect transition at national government level (Holscher, 2015) and also at EU level (Climate-KIC, 2015).

However, the level of theorising in this body of literature is frequently high level. The MLP provides a policy relevant high level framework for driving transitions with a normative thrust; implicitly 
conceiving of success as a significant change in the sociotechnical system towards a more sustainable configuration (Verbong and Geels, 2007, Loorbach and Rotmans, 2006, Witkamp et al., 2011). This is problematic because it assumes a stability of narrative. Rotmans et al. (2001) contend that an understanding of transitions at regime level can be used by policy makers to drive such a transition, however, these policy makers are often working in a changing political context which may vary in its commitment to sustainability and carbon reduction. For example, the UK has seen a complete change in energy policy in the past decade; generous subsidies for renewable energy were introduced then significantly reduced within 5 years, and government discourse has become less committed to sustainable energy and more committed to (unsustainable) energy security and affordability (Geels, 2014). This instability is reflected internationally as green growth stimulus packages instigated after the 2007 financial crash come to an end and give way to austerity economics; leading to less investment in sustainability innovations (Frankfurt School - UNEP and Bloomberg New Energy Finance, 2011).

In such changing political economic contexts, transitions are unlikely to be 'managed' in a long term, high level manner. It is therefore important to look at smaller scales of enquiry. At this scale, it becomes apparent that projects that in effect push transitions forward often operate without explicit transition aims and with a range of different logics. Such projects may not all benefit from the insights of the MLP, and as such, a theoretical understanding of this smaller scale may prove more fruitful in effecting transition. An emerging body of literature is starting to look at these smaller scales of enquiry, such as regional initiatives (Essletzbichler, 2010), cities (Hodson and Marvin, 2012), and small rural projects (Heiskanen et al., 2015). This literature is beginning to demonstrate that it is important to capitalise on projects happening on the ground, rather than relying on transition to be driven from higher levels of governance.

This paper contributes to this emerging debate by looking at local projects for sustainable energy in practice. The concept of success is used as a vehicle for understanding the practice of two urban sustainable energy projects based in Birmingham, UK. These projects are trying to address and are being carried out within "wicked problems"; a concept defined by Rittel and Webber (1973) and applied to sustainability by Ison (2010). This concept is applied here to highlight better the nature of the problem that individuals within local projects are facing, within the broader sociotechnical system. Wicked problems cannot be definitively formulated; are interconnected to other problems; have no 'right or wrong' answers, and are difficult to resolve, involving 'high stakes' and requiring a change in thinking and action across a number of different groups. In such problems, success is not always obvious.

Our research question is therefore: how is success perceived in local projects for sustainable energy, and what are the implications of this for the theory and practice of sustainability transitions? First a 
brief review of sustainability transitions will be given, followed by a review of emerging literature highlighting the importance of a more granular focus on projects and individuals. The case studies are then introduced. The subsequent data and analysis uses the concept of 'causative beliefs' to make sense of the competing perceptions of success demonstrated within these projects. The implications of the findings for practice and theory are then discussed.

\section{Understanding local sustainable energy projects: socio-technical systems and individuals in projects}

The sustainable transition literature focuses on high level social and socio-material interactions, which sets a framework in which to think and set projects for sustainable energy. This conceptualises societal functions, such as transportation, housing, communication, energy and food production, as provided by systems comprised of technologies, supporting institutional and regulatory infrastructures, natural resources, and cultural expectations (Rip and Kemp, 1998, Geels, 2002). These components are interdependent but tend to maintain the status quo. Rip and Kemp (1998) refer to this as a sociotechnical 'regime' in which technical components co-evolve with social elements through a process of mutual adaptation and feedback. The system as a whole becomes stable and inert as it matures (Lovell, 2005). Thus society becomes 'locked in' to a given regime as the status quo is reinforced (Unruh, 2000); the regime becomes irreversible since the technology is proven and ubiquitous, the infrastructure and legal structure is set up to support it and the wider system, and users know what to expect from the system and how to use the technologies within it. Furthermore, the technology itself contributes to this by 'scripting' or prescribing certain behaviours, for environmental good or ill (Latour, 1992). Stable social

practices form both in end-user energy use and in those acting within the regime (Shove, 1998, Hargreaves et al., 2013).

Rip and Kemp (1998) explain how despite this stability socio-technical systems can change through their 'Multi-Level Perspective' (MLP). This describes three levels - a micro, meso and a macro level; respectively the niche, the regime and the landscape. The sociotechnical regime sits at the meso level, and is the site of incremental innovation and dynamic games within and between regime actors. At the macro level is the sociotechnical landscape; a stabilised backdrop which exerts influence, and which is difficult to change (Geels and Schot, 2007). Technology, or the material culture of societies is part of this landscape, as are shared cultural beliefs, symbols and values. At the micro level there are technological or innovation 'niches', which some argue are the site of radical innovations with the potential to change the regime completely (Kemp et al., 1998). These are protected spaces shielding new innovation from the regime until they are ready to compete with it, and historical case studies give examples of such niches replacing the incumbent regime (Geels, 2006). Work on Strategic Niche Management has shown these niches to be a fruitful area for analysis in understanding how varied 
motivations between actors operate at project or sector levels, and that they can be deliberately set up to attempt regime transition; (Kemp et al., 1998, Witkamp et al., 2011). There are also other methods to effect transition which do not focus on a particular innovation, but attempt to encourage transitions, sometimes from a high governance level (Loorbach and Rotmans, 2010).

This body of literature does see a world of competing positions, but focuses on the abstract level of the difficult to change regime. It therefore perceives success as a change in this abstract system, to one that is more sustainable. This systemic view is helpful in understanding the problem at this abstract level, but it does not relate easily to practice as its scope is so broad. Strategic Niche Management does explore smaller scales (see Ieromonachou et al., 2007), but its implications for transition (such as opportunities for experimentation and second order learning) remain high level. This is beginning to be tackled by literature emphasising the role that smaller spatial scales have and can play in the development of sustainable energy futures. Spath and Rohracher (2010) discuss the use of 'guiding visions' in the 'energy region' of Murau, in successfully guiding and co-ordinating local activities. Essletzbichler (2010) and (2012) discuss how smaller spatial scales such as cities and neighbourhoods may desire to use what smaller powers they have to transform their mobility, housing, food and energy systems to more sustainable forms. Projects at this level, they argue, can act as niches or protected spaces for providing guiding visions, for satisfying local need and promising exportable lessons, products and services.

A focus on local projects emphasises the sheer difficulty of delivery given the barriers that project teams face, particularly when those teams are voluntary (Bomberg and McEwen, 2012), and how this can sometimes stall projects (Smith, 2007). Such a focus also highlights different project goals than assumed in the higher level transition literature. For example, Dóci et al. (2015) identify renewable energy projects which exemplify 'social niches'; oriented towards meeting local needs or wishes, rather than inducing transition, and work by Heiskanen and others emphasises the importance of social support and demonstrating the prevalence of social norms for reducing energy use and adopting renewable energy technologies (Jalas et al, 2014, Heiskanen et al 2010). Heiskanen et al. (2015) have recently looked at local projects from the point of view of 'non technologists' (i.e. not sustainable technology proponents explicitly working to induce transition). Interrogating the concept of experimentation as part of strategic niche management, they point out that ordinary people judge experimentation on different criteria than transition scientists, and that failure to provide 'proof of principle' on new technologies and practices can have longer term, damaging local consequences. This is supported by Judson et al (2015) and Nyborg (2015) who report some resistance to or subversion of heat pumps or smart grid technologies where they do not fit with household practices. This literature starts to critique the essentially purposive nature of transitions, as conceived by the previous literature reviewed here. 
At the scale of projects, different stakeholders may have other motivations or priorities than effecting transitions, faced as they are with the 'messiness' of project delivery, local contexts and everyday life.

By focusing on the practice of local projects, individuals are forced into view. Yet the role of individuals in socio technical systems continues to be problematic. Farla et al. (2012) point to criticisms of sustainability transitions for not adequately conceptualising individual agency. Despite work addressing this (Penna and Geels, 2012), individuals, important as the locus of agency, are often still 'lost' in descriptions of process or groups. This is particularly the case when looking at individuals who are not part of the technological regime, but rather are 'technology users'. The way in which these people use technologies in their daily lives and their reasons for doing so is rarely explored in the sustainability transitions literature (Shove and Walker, 2007), instead the focus is often on actors within the technological side of the regime (Zhang, 2016). Focus on this social group of 'technology users' comes from other scholarly areas, such as social practice theory (Pullinger et al., 2014). Social practice theory sees energy use as a by-product of the nexus of routines, materials, competencies and meanings involved in everyday life, such as washing, space heating and communicating (Shove, 2003). There is little discussion of interactions between technology users, and technological regime actors.

For this social group within the energy socio-technical regime, it is common to hear debate on the need for 'behaviour change'. Some of the behaviour change literature makes rather unhelpful assumptions about energy users as rational, utility maximising decision makers, who only make poor decisions as a result of information deficit (Torriti et al., 2010). Scholarly understanding of behaviour change is increasingly more complex and socially informed, demonstrating the importance of norms, appropriate feedback and unconscious habits (Cialdini, 2003, Darby, 2006, Maréchal, 2010). This complexity of energy behaviour and its constraints is well conceptualised within the sociotechnical systems literature. However, away from academia in the messiness of practice, 'folk' understandings of behaviour change resting on information deficit models, and in some cases social norming, prevail as preferred explanatory tools. This is exemplified by ongoing European-wide projects to implement smart grids and the role of smart meters within that (EU, 2011), and recent UK information campaigns to cut carbon emissions (such as 'Act on Climate Change'; Directgov, 2011). In such projects, success is seen as simply the achievement of behaviour change.

These additions to the literature problematize the idea of success in various ways. Individual projects carried out and experienced by a number of individuals over a short time period are of course not achieving 'transition' at the system level. And yet while interacting with the wicked problem of an unsustainable and inequitable energy system; questions of success and failure are still relevant. Projects are still judged to be successful (or not), at the level of the project itself, and at the level of the individuals participating in that project, and at the level of the locality overall. A theoretical 
understanding at this level is therefore useful if these 'messy' local projects can nevertheless be capitalised upon to effect transition.

\section{Methodology}

These ideas were explored with case studies in order to bring out practical aspects of change and context. Two Birmingham based local sustainable energy projects were explored. A critical realist approach was adopted, as articulated by Bhaskar (1978). This holds that there is an external reality brought about by generative mechanisms, including social generative mechanisms. Elements of grounded theory (Strauss and Corbin, 1998) were used to guide the systematic exploration of the processes of the projects, in order to fully understand the nature of success in a local context. The case studies were also longitudinal, allowing an understanding of how the problems faced by the projects changed over time. The case studies chosen were the Birmingham Energy Savers (BES) project run by Birmingham City Council, and the Green Streets project run by Sustainable Moseley (SusMo). Case selection was partially pragmatic; both projects had recently begun at the time of the research, both were based in the same urban environment (Birmingham) and hence were more comparable. However, as BES was a local authority-led project and Green Streets a volunteer project, the difference in size, organisational form and resources meant they could be used as 'maximum variation cases' (Flyvbjerg, 2006).

\subsection{The Two Cases - BES and SusMo}

Birmingham Energy Savers began in 2010 as a Birmingham City Council (BCC) pilot project installing photovoltaic (PV) panels onto council properties in order to tackle fuel poverty, re-energise the local economy and reduce carbon emissions. In total, 1300 PV arrays were installed in deprived areas by 2012. BCC paid for these installations through claiming the Feed-in Tariff, which had been introduced in April 2010 to encourage the installation of microgeneration technologies. This project was being carried out with the aim of moving from PV to 'whole house solutions' under then incoming UK Green Deal legislation, through which BCC hoped to address a number of social and economic aims.

SusMo embarked upon their project officially in 2009 , after having won $£ 140,000$ worth of goods and services from British Gas as part of their Green Streets project; one of 14 winners nationally. With this resource, SusMo arranged for the installation of PV arrays on a local church, a school, a mosque and a building in the local allotments, and other microgeneration technologies or energy efficiency measures to be installed in 17 houses (the actual work for which was carried out by British Gas or their contractors). Moseley is a vibrant, multicultural neighbourhood community boasting a monthly farmers' market, yearly music festivals and a large number of community groups. 


\subsection{Data Collection and Analysis}

Table 1 gives an overview of the methods used. Both case studies were followed for a period of 18 (SusMo) to 22 (BES) months, during which time monthly board or committee meetings were attended in order to observe the organisers of each project in a natural setting, allowing the researcher to remain in the 'flow' of everyday life (Kearns, 2010). Documents were also gathered both to provide an initial understanding of the case studies, and also to provide specific figures and minute detail.

\section{Table 1 about here}

Interviews formed the most important source of case study information as they targeted people directly involved with the cases, allowing the development of detailed insight (Yin, 2003). Interviews with both the organisers and beneficiaries of each project were carried out in spring 2011, when the beneficiaries' involvement with the projects had just begun, and again roughly 12 months later. Some interviewees were changed or added in round two as their roles emerged as being important. Both sets of questions aimed to understand how the beneficiaries responded to the interventions in terms of their behaviour, their reasons for participating, and the organisers themselves. How contextual factors mediated the beneficiaries' responses to the interventions was also explored. Interviews with the organisers sought to understand the perceptions that the organisers held about those beneficiaries, about their energy behaviour and how this could be changed, and what contextual factors came into play. The data was reviewed and a number of analytical categories were developed inductively from the data to reflect these themes. All interviews were coded according to this list of categories, which grew as the data required.

\subsection{Analytical Framework of Success}

Success emerged as a key analytical concept from the data which both gives an understanding of practice and a signpost for better future projects. Fundamentally different beliefs are held about the nature of the problem faced by projects; these beliefs are here termed 'causative beliefs' as they determine the perception of outcomes. Essentially the problem to be addressed is what a person believes it to be, or at least believes is the most important. This belief is fundamentally tied to a belief about what success is - being the resolution of that problem. Both are tied to beliefs about what the solution is, i.e. what mechanisms will resolve this problem. These three elements are three parts of the same mental construct; a triplet. When talking about these projects, participants perceived them as successful if the project had solved the problem as they had perceived it. If it had not, they viewed the project as a failure. Sometimes different organisers of the same project had opposing views on this. Sometimes 
there were hidden objectives, or objectives contradicted each other. All of these contribute to the wickedness of the problem.

\section{Results}

Projects are ultimately about resolving problems, and therefore the results are laid out below according to the problems perceived by the participants of the project (see Table 2) rather than according to the problems framed in section 2 of this paper. Each problem and the triplet of causative beliefs of which it is part will be taken in turn and the data for each given. It is acknowledged that there is much overlap.

\section{Table 2 about here}

\subsection{Fuel poverty}

That many of Birmingham's residents suffered from fuel poverty was considered a major problem that both projects wished to address at the same time as delivering sustainable energy. The organisers of both projects were forthcoming about this wish, and beneficiaries most often gave this reason for choosing to participate in the projects.

\footnotetext{
"most of the PV in Birmingham is on social housing, and was done for fuel poverty reasons" (BES organiser)

"Our main aim as a group was to help people who are in fuel poverty, to stress that the people in need were the people who should get the insulation and things like that" (SusMo Member)

"I thought we'll have a go and see if it saves any money . . Every little penny counts these days" (BES beneficiary)
}

The solution to this problem was to essentially alleviate people from fuel poverty. The way in which these projects tried to do this was by installing energy saving measures and trying to change behaviour.

\footnotetext{
“The PV panels were 'sold' as a mechanism for saving money” (BES organiser)

"The best way of getting people to save money on their fuel bills is to make them change their behaviours that are giving higher electricity bills. For some vulnerable occupiers that is not possible” (BES organiser)
}

Success given this perception of and causative belief about the problem was therefore reduced bills for project beneficiaries, and their alleviation from fuel poverty.

\subsection{Overuse of energy}


At another level, the problem can be seen as that it is normal for people in the UK to use too much energy. SusMo, being a low carbon action group, took this to be its primary problem because this is environmentally unsustainable. Although, as the above quotes demonstrates, they were additionally concerned for the economic unsustainability for low income households, this was secondary to environmental aims. However, for BES, the economic unsustainability was the primary problem because the cost of this energy was becoming unmanageable for tenants.

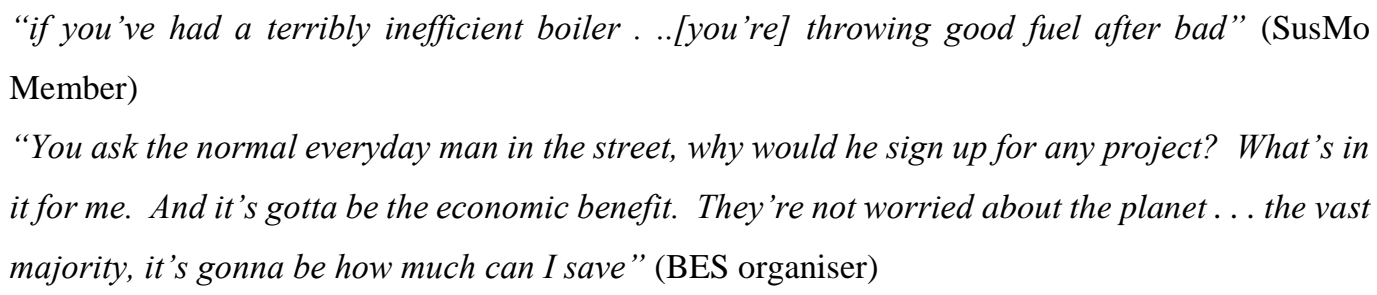

The solution to this problem was to reduce the energy being used. This could be done again through installing physical energy efficiency measures which would reduce the energy used and hence the financial and environmental cost associated with this.

\author{
“[BES was] very much targeted at disadvantaged households” (BES organiser) \\ "Fuel will be saved by happenchance. . That's what the technology's for, but to get the best out \\ of something you want people to understand it” (SusMo member)
}

Another potential solution to this problem was to encourage people to change their wasteful energy behaviours, perhaps through social norms. There was some evidence that these norms were starting to take effect.

\footnotetext{
“I'm a great believer in the 'people like me' effect. .it's saying there's a lot of people round here who are doing this . . . it's not rich people, it's not eco-activism, it's about saying actually this is really normal” (SusMo member)

“We've had properties, we call it PV envy, er, where some properties are unsuitable .. [they will] chase you, why can't I have em on mine, I need to know the reason" (BES organiser)
}

Success given this perception of the problem was reduced energy consumption. However the connection to, and at some points the contradiction with, the first problem of fuel poverty is never addressed within the projects.

\title{
4.3 Unsustainable lifestyles
}

A third causative belief about the nature of the problem that these projects were aiming to tackle was that many people have unsustainable lifestyles which need to change. 
"People [need to realise] the importance of not driving cars around for short distances and stop buying everything encased in plastic" (SusMo member)

The solution to this problem was perceived as increasing awareness of environmental sustainability through visible sustainable energy technologies such as PV and through education and information which would lead to behaviour change.

"The reason was to get the word out, to get people interested, I mean the flagship was obviously the church, that was the thing that we thought . . will catch everyone's eye . . that'll be a big thing" (SusMo member)

They can see the [PV generation] meter go backwards, they're generating, they can see that, why have I got 50watt halogen light bulbs, when I turn two of them on, that takes all the power from my $P V$. I should get some energy efficient ones" (BES organiser)

Success given this perception of the problem was viewed as something of a 'conversion' to environmental sustainability and advocacy;

"we had also hoped that our core group of people would be greatly enlarged with all these people who had been inspired by everything” (SusMo organiser)

Although not contradictory to other problems, this potentially uncompromising stance reduces freedom for action in relation to the ways projects can be delivered.

\subsection{Delivering complex projects for change}

A fourth causative belief as to what is the primary problem is quite simply, delivering large and/or complex projects are in themselves extraordinarily difficult to do and require marshalling people and resources against a backdrop of changing circumstances and often pathological accountability. This was made difficult for BES as a project within a large local authority, where resources are often severely limited but the number of stakeholders and different concerns, who must be satisfied, are many. The delivery of a project was difficult for SusMo to do as a voluntary community group because most members had full time day jobs and hence had little free time and resources to devote to this demanding task of project management.

"It took a lot of work going round politicians and senior management, again and again, because it doesn't make sense in the first instance” (BES organiser) 
“. . the workload . it was more than we as volunteers could cope with, and I was the only one of the core group who was actually retired, everybody else had jobs and kids . we didn't realise the implication on our personal lives" (SusMo co-ordinator)

"The downside is burnout, for a few individuals ... I wouldn't go through with it again. Full stop" (SusMo co-ordinator)

The solution to this problem for BES was based on professional experience which allowed them to manage uncertainty by bringing together the right people and to include a number of key aims to please different stakeholders. The ensuing tension was used to drive practical and timely decisions.

"When I set up the board for the programme, I set up three champions, a social benefit champion, an environmental champion, and an economic champion. I had a tension. Now the reason that that's important was that some of the decisions that you have to make are between those" (BES organiser)

For SusMo, the solution to this problem was simply 'bloody minded' dedication on behalf of a few individuals.

"SusMo . . . as an organisation . . may only be hanging on by their fingertips, if I can say that, ... or by four or five or six dedicated people . . but I think we should hang on" (SusMo beneficiary)

Success given this perception of the problem is therefore the achievement of the delivery of the projects in question. At its worst a focus on project delivery can overshadow the other problems, merely delivering material targets. On the other hand, not delivering anything until perfection is achieved is a waste of time.

\subsection{Few economic opportunities in Birmingham}

A final causative belief about the nature of the problem that these projects felt they had to address was that Birmingham as a city suffers from high levels of deprivation, with the reason being the lack of jobs in the city. This had become a pressing issue since the closure of the Longbridge car manufacturing plant, and the demise of manufacturing and industry in general (Larkham, 2003)

"We've got the highest levels of unemployment in the country! It's not good for the city! Unemployment is linked to poverty, violence, crime, mental health, public health" (BES organiser)

The solution to this problem was perceived as working towards regenerating the city's economy, in this instance through construction for energy efficiency. 
"The reason it's such a lovely project is that [as well as social and environmental benefits] it delivers job creation and inward investment” (BES organiser)

Success according to this perception of the problem was therefore simply to create more local jobs. This contradicts all of the other problems except possibly bringing work to those in fuel poverty. However, delivering on this is complex because of procurement regulations and the demands of using an under-skilled workforce.

It can be seen, therefore, that within both of these local sustainable energy projects, there were a number of different causative beliefs about the full nature of the problem that each project was trying to address, thus calling into question the nature of success, and so the best mechanisms to get from problem to success. Some of these causative beliefs have little to do with sustainable energy per se, but were important in the local context where these projects had to be successful. In this way, the projects were addressing a 'wicked' problem; a problem which is stakeholder dependent and hence with little agreement as to what the problem actually is.

\section{Discussion}

Success is a useful vehicle for understanding the practice of local sustainable energy projects. Ultimately, success of any kind in such projects is difficult to achieve as a result of the systemic nature of the problem of unsustainable energy provision. However, often local sustainable energy projects deal with more "immediate" concerns than environmentally driven desires for a sustainability transition, and therefore success is tied to the particular problem that each individual within the project is prioritising. Hence, a focus on the practice of local projects forces a number of different understandings of success into view, that are not normally addressed in the sustainability transitions literature.

The analysis of the data demonstrates that there are many different causative beliefs and hence different perspectives of success within individual sustainable energy projects. Success can be conceived of as simply the achievement of delivery of a local sustainable energy project, as this is a feat in itself. This is even more the case when dealing with competing concerns with few resources. Installing sustainable energy technologies is also indicative of success; it can make an instant difference to the individual householder as it can lift them from fuel poverty. If such technologies are visible, they can potentially affect the behaviour of others, and change expectations about how energy is normally sourced and what technologies are required for the home. Energy behaviour change is itself another conception of success, both reducing individual impact on the environment and saving householders money. Finally, this research also finds that local sustainable energy projects are considered successful if they create jobs or alleviate economic hardship. Success here is economic and quantifiable. Alleviation from fuel 
poverty was a critical conception of success in both projects, so too was the creation of employment opportunities. This latter understanding of success further emphasises the hitherto poorly understood role of the locality in sustainable transitions. Economic deprivation is a particular issue within Birmingham (and in many other cities), and as such BES, as a publically funded project, had to address this in order to be considered successful. In other localities, a primary concern in a sustainable energy project might be preserving the heritage of the built environment (e.g. Bath, see Anderson and Robinson, 2011), or self-sufficiency (e.g. the Scottish Highlands, see Mackenzie, 2006). Through looking at these multiple perspectives of success, real tensions can be seen in how success is perceived by different individuals even within the same projects.

This summary of the narratives of success in these projects demonstrates the full nature of the wicked problem they were facing. Ison (2010) describes 'wicked problems' as going beyond the capacity of any one organisation to understand and respond to, and where there is often disagreement about the causes of these problems and the best way to tackle them. Because of this, there is always a propensity to apparently 'tame' the problem by reducing it to a single manageable problem which can be defined, and solutions for which can be tested. Thus, in these projects different individuals are tempted to cope with the wicked problem of unsustainable energy by focusing on their own causative beliefs about the problem and about success. By exploring the scale of local sustainable energy projects, this research adds to the sustainability transitions literature by looking at how this was done in practice.

There are important implications to understanding the practice of local projects and their multiple narratives of success. The "birds eye" policy frame of the transition literature is not necessarily always relevant to local projects, where different actions and framings are often needed to drive action forward, and where projects are constantly happening but not in the 'protected spaces' of niches for the express purpose of contributing to transition. Theoretically, this challenges the relevance that the sustainability transition literature claims to have for policy; at what level is it relevant, and how far? Local politics and projects require the development of a more nuanced and detailed understanding of how to drive transition, not currently provided.

This paper contributes to this by arguing that local projects can provide the necessary 'stepping stones' towards that transition, even if they do not 'look' like sustainability transition projects. If it can be argued that individual projects do make a difference at some level of the wider (sustainability) problem, then they can followed up with another project with similar aims, which can capitalise on the small change created by the previous project, and create further change allowing yet another project to take place. Individual projects happen in a locality, to individuals with certain causative beliefs. Local projects must therefore start 'where those individuals are', and design projects which suit the context and options that are actually available there. Perceived success can create opportunities for more radical 
projects. This research also suggests that if some individuals do not perceive the project to be successful, then they are likely to reject proposals for further projects that attempt to build on the first, thereby holding back the wider transition process. SusMo's co-ordinator saying; "I wouldn't go through with it again. Full stop" is an example of this. This is supported by Heiskanen et al (2015), who suggest that theoretical views or guiding visions of transitions are almost irrelevant to actual delivery; local projects and individuals can and will dismiss them if they are not perceived as positive locally.

Ultimately, change is incremental and episodic (see Spinardi and Slayton 2015 for a demonstration of this in aviation); this paper argues that individual projects can create a trajectory of change when they build on each other and reinforce similar messages. This paper thereby contributes to a growing body of work demonstrating alternative insights for sustainability transitions that do not rely on the MLP's high level insights, (see also Hyysalo et al (2013)'s work on the role of internet forums in the spread of heat pumps in Finland, and Heiskanen et al (2014)'s call for co-production of knowledge to improve sustainable consumption policy). This linking of messy local projects with a variety of different aims (other than transition) over time is another way towards a wider transition that is not well explored within the current transition theory and practice.

This research also demonstrates the need to better heed Shove and Walker's (2007) critique of the normative nature of transition. It is futile to conceive of transitions as a move from system or innovation A to system or innovation B. The case studies presented here demonstrate that within a process of change there will be a multiplicity of narratives about what constitutes 'success' for a project. At times these narratives may be contradictory. These multiple narratives of success can be an opportunity, rather than a difficulty. Understanding this allows us to recommend that projects be multi-faceted, so there are more available potential narratives of success. Within transition theory and practice as a whole, we therefore call for pluralism in the pursuit of transitions.

\section{Conclusion}

This research demonstrates that there are many different causative beliefs and hence different conceptions of success. The data suggest that it is more likely that projects which are multi-agenda, thereby allowing for pluralism in causative beliefs about success, will be perceived as successful. Local projects are not always 'protected spaces' to explore suitable innovations for a sustainability transition; they are focusing on the messy and wicked problems of their locality. However they can still make a contribution to transition if perceived as successful and built upon. And yet, within the world of transition practice, attempts to encourage transitions often take a high level, vision-led approach (Kemp and Loorbach, 2003 Climate-KIC, 2015). However, in some national contexts a high-level managed 
approach may not be easy (Hawkey and Webb, 2014). In such contexts, individual local projects with non-explicit sustainability transition aims, can provide a way forward.

Sustainable transition research and practice would therefore benefit from this reconceptualization away from success as concerned with bringing about full sustainability transitions, and to focus on local projects as sites of change. Such a reconceptualization provides transition theory with a new way of understanding how transitions can happen, and provides practical advice on effecting transitions. A focus on local projects forces individuals and localities into view and demonstrates that in practice, by emphasising narratives of success, local projects can attract support and goodwill that will help build momentum for the next project. This is borne out by the projects discussed here; following the successful completion of SusMo's Green Streets, SusMo set up a renewable energy mutual, and following the success of BES support was given for an ambitious extension of the project. This positive narrative understanding of success is the sort of dynamic understanding needed to capitalise on projects, allowing transition to emerge on a project by project basis.

\section{References}

Anderson, W. \& Robinson, J. 2011. Warmer Bath: A guide to improving the energy efficency of traditional homes in the city of Bath. Bath: Centre for Sustainable Energy and Bath Preservation Trust.

Bhaskar, R. 1978. A Realist Theory of Science Hemel Hempstead, Harvester.

Bomberg, E. \& McEwen, N. 2012. Mobilizing Community Energy. Energy Policy, 51, 435-444.

Cialdini, R. B. 2003. Crafting Normative Messages to Protect the Environment. Current Directions in Psychological Science, 12, 105-109.

Climate-KIC. 2015. Climate-KIC Projects [Online]. Available: http://www.climatekic.org/projects/\#Innovation [Accessed 7th July 2015 2015].

Darby, S. 2006. The Effectiveness of Feedback on Energy Consumption. A review for DEFRA of the literature on metering, billing and direct displays.

Directgov. 2011. Environment and Greener Living: Climate Change [Online]. Available: http://www.direct.gov.uk/en/Environmentandgreenerliving/Thewiderenvironment/Climatec hange/index.htm [Accessed 24th October 2011.

Dóci, G., Vasileiadou, E. \& Petersen, A. C. 2015. Exploring the transition potential of renewable energy communities. Futures, 66, 85-95.

Essletzbichler, J. 2010. Renewable Energy Technology and Path Creation: A Multi-scalar Approach to Energy Transition in the UK. European Planning Studies, 20, 791-816. 
EU 2011. Smart Grids: From Innovation to Deployment. Brussels: EU.

Farla, J., Markard, J., Raven, R. P. J. M. \& Coenen, L. 2012. Sustainability transitions in the making: A closer look at actors, strategies and resources. Technological Forecasting and Social Change, 79, 991-998.

Flyvbjerg, B. 2006. Five Misunderstandings About Case Study Research. Qualitative Inquiry, 12, 219245.

Geels, F. W. 2002. Technological transitions as evolutionary reconfiguration processes: a multi-level perspective and a case-study. Research Policy, 31, 1257-1274.

Geels, F. W. 2006. The hygienic transition from cesspools to sewer systems (1840-1930): The dynamics of regime transformation. Research Policy, 35, 1069-1082.

Geels, F. W. 2014. Regime Resistance against Low-Carbon Transitions: Introducing Politics and Power into the Multi-Level Perspective. Theory Culture and Society, 0, 1-20.

Geels, F. W. \& Schot, J. 2007. Typology of sociotechnical transition pathways. Research Policy, 36, 399417.

Hargreaves, T., Nye, M. \& Burgess, J. 2013. Keeping energy visible? Exploring how householders interact with feedback from smart energy monitors in the longer term. Energy Policy, 52, 126134.

Hawkey, D. \& Webb, J. 2014. District Energy Development in Liberalised Markets: situating UK heat network development in comparison with Dutch and Norwegian case studies. Technology Analysis and Strategic Management, 26(10), 1228-1241.

Heiskanen, E., Johnson, M., Robinson, S., Vadovics, E., Saastamoinen, M. 2010. Low-carbon communities as a context for individual behavioural change. Energy Policy, 38(12), 7586-7595.

Heiskanen, E., Mont, O., \& Power, K. 2014. A Map Is Not a Territory - Making Research More Helpful for Sustainable Consumption Policy. Journal of Consumer Policy, 37, 27-44.

Heiskanen, E., Jalas, M., Rinkinen, J. \& Tainio, P. 2015. The local community as a "low-carbon lab": Promises and perils. Environmental Innovation and Societal Transitions, 14, 149-164.

Hodson, M. \& Marvin, S. 2012. Mediating Low-Carbon Urban Transitions? Forms of Organization, Knowledge and Action. European Planning Studies, 20, 421-439.

Holscher, K. 2015. From niche to mainstream - how to spread sustainable practices [Online]. Dutch Research Institute for Transitions. Available: http://www.drift.eur.nl/?p=9284 [Accessed 7th July 2015 2015].

Hyysalo, S., Juntunen, J. K. \& Freeman, S. 2013. Internet Forums and the Rise of the Inventive Energy User. Science and TEchnology Studies. 26(1) 25-51. 
IPCC (ed.) 2014. Summary for Policymakers, Cambridge, UK and New York, USA.: Cambridge University Press.

leromonachou, P., Potter, S. and Warren, J. 2007. Analysing road princing implementation processes in the UK and Norway. European Journal of Transport and Infrastructure Research, 7(1), 1538

Ison, R. 2010. Systems Practice: How to Act in a Climate-Change World, London, Springer.

Jalas, M., Kuusi, H. \& Heiskanen, E. 2014. Self-Building Courses of Solar Heat Collectors as Sources of Consumer Empowerment and Local Embedding of Sustainable Energy Technology. Science and Technology Studies 27(1), 76-96

Judson, E. P., Bell, S., Bulkeley, H., Powells, G. \& Lyon, S. 2015. The Co-Construction of Energy Provision and Everyday Practice: Integrating Heat Pumps in Social Housing in England. Science and Technology Studies, 28(3) 26-53.

Kearns, R. A. 2010. Seeing with Clarity: Undertaking Observational Research. In: Hay, I. (ed.) Qualitative Research Methods in Human Geography. Third Edition ed. Canada: Oxford University Press.

Kemp, R., Schot, J. \& Hoogma, R. 1998. Regime Shifts to Sustainability Through Processes of Niche Formation: The Approach of Strategic Niche Management. Technology Analysis and Strategic Management, 10, 175-195.

Larkham, P. 2003. Birmingham, Sheffield, Geographical Association.

Latour, B. 1992. Where Are the Missing Masses? The Sociology of a Few Mundane Artifacts. In: Bijker, W. \& Law, J. (eds.) Shaping Technology. Cambridge, MA: MIT Press.

Loorbach, D. \& Rotmans, J. 2006. Managing Transitions for Sustainable Development. In: Olsthoorn, X. \& Wieczorek, A. (eds.) Understanding Industrial Transformation. Springer

Loorbach, D. \& Rotmans, J. 2010. The practice of transition management: Examples and lessons from four distinct cases. Futures, 42, 237-246.

Lovell, H. 2005. Supply and Demand for Low Energy Housing in the UK: Insights from a Science and TEchnology Studies Approach. Housing Studies, 20, 815-829.

Mackenzie, A. F. D. 2006. "'S Leinn Fhèin am Fearann" (The land is ours): re-claiming land, re-creating community, North Harris, Outer Hebrides, Scotland. Environment and Planning D: Society and Space, 24, 577-598.

Maréchal, K. 2010. Not irrational but habitual: The importance of "behavioural lock-in" in energy consumption. Ecological Ecnomics, 69, 1104-1114.

Nyborg, S. 2015. Pilot Users and Their Families: Inventing Flexible Practices in the Smart Grid. Science and Technology Studies. 28(3), 54-80. 
Penna, C. C. R. \& Geels, F. W. 2012. Multi-dimensional struggles in the greening of industry: A dialectic issue lifecycle model and case study. Technological Forecasting and Social Change, 79, 9991020.

Pullinger, M., Lovell, H. \& Webb, J. 2014. Influencing household energy practices: a critical review of UK smart metering standards and commerical feedback devices. Technology Analysis \& Strategic Management, 26, 1144-1162.

Rip, A. \& Kemp, R. 1998. Technological Change. In: Rayner, S. \& Malone, E. (eds.) Human Choice and Climate Change: Resources and Technology. Columbus, Ohio: Battelle Press.

Rittel, H. W. \& Webber, M. M. 1973. 2.3 planning problems are wicked. Polity, 4, 155-69.

Rotmans, J., Kemp, R. \& van Asselt, M. 2001. More evolution than revolution: transition management in public policy. Foresight, 3, 15-31.

Seyfang, G. \& Longhurst, N. 2016. What influences the diffusion of grassroots innovations for sustainability? Investigating community currency niches. Technology Analysis \& Strategic Management, 28, 1-23.

Shove, E. 1998. Gaps, barriers and conceptual chasms: theories of technology transfer and energy in buildings. Energy Policy, 26, 1105-1112.

Shove, E. 2003. Converging Conventions of Comfort, Cleanliness and Convenience. Jornal of Consumer Policy, 26, 395-418.

Shove, E. \& Walker, G. 2007. CAUTION! Transitions ahead: politics, practice and sustainable transition management. Environment \& Planning A, 39.

Smith, A. 2007. Emerging in between: The multi-level governance of renewable energy in the English regions. Energy Policy, 35, 6266-6280.

Smith, A., Voss, J. \& Grin, J. 2010. Innovation Studies and Sustainability Transitions: The allure of the multi-level perspective and its challenges. Research Policy, 39, 435-448.

Späth, P. \& Rohracher, H. 2010. 'Energy Regions': The transformative power of regional discourses on socio-technical futures. Research Policy, 39, 449-458.

Spinardi, G. \& Slayton, R. 2015. Greener Aviation Take-off (Delayed): Analysing Environmental Transitions with the Multi-Level Perspective. Science and Technology Studies, 28(1), 28-51

Strauss, A. L. \& Corbin, J. 1998. Basics of Qualitative Research: Techniques and Procedures for Developing Grounded Theory, California, London, New Delhi, Sage Publications.

Torriti, J., Hassan, M. G. \& Leach, M. 2010. Demand response experience in Europe: policies, programmes and implementation. Energy, 35, 1575-1583.

Unruh, G. C. 2000. Understanding Carbon Lock-in. Energy Policy, 28, 817-830. 
Verbong, G. \& Geels, F. 2007. The ongoing energy transition: Lessons from a socio-technical, multilevel analysis of the Dutch electricity system (1960-2004). Energy Policy, 35, 1025-1037.

Witkamp, M. J., Raven, R. P. J. M. \& Royakkers, L. M. M. 2011. Strategic niche management of social innovations: the case of social entrepreneurship. Technology Analysis \& Strategic Management, 23, 667-681.

Yin, R. K. 2003. Case Study Research: Design and Methods, Thousand Oaks, London, New Delhi, Sage Publications.

Zhang, M. Y. 2016. Meso-level factors in technological transitions: The development of TD-SCDMA in China. Research Policy, 45, 546-559.

Table 1 - Data collected for the two case studies

\begin{tabular}{|l|l|l|l|}
\hline Case studies & Interviews & $\begin{array}{l}\text { Observation } \\
\text { (meetings, site visits) }\end{array}$ & Documents \\
\hline BES & 36 & 38 & $\begin{array}{l}\text { Minutes from board meetings, reports, } \\
\text { letters, business plans, project proposals }\end{array}$ \\
\hline SusMo & 26 & 25 & $\begin{array}{l}\text { Minutes from board meetings, reports, } \\
\text { letters, business plans, project proposals }\end{array}$ \\
\hline
\end{tabular}

Table 2 - Table of Causative Beliefs

\begin{tabular}{|c|c|c|}
\hline Problem & Solution & Success \\
\hline Fuel poverty & $\begin{array}{l}\text { Installation of energy } \\
\text { efficiency measures and/or } \\
\text { behaviour change }\end{array}$ & Alleviation from fuel poverty \\
\hline Overuse of energy & $\begin{array}{l}\text { Installation of energy } \\
\text { efficiency and/or behaviour } \\
\text { change }\end{array}$ & Reduced energy consumption \\
\hline Unsustainable lifestyles & $\begin{array}{l}\text { Increasing awareness of } \\
\text { sustainability. }\end{array}$ & $\begin{array}{l}\text { 'Conversion' to environmental } \\
\text { sustainability and advocacy. }\end{array}$ \\
\hline $\begin{array}{l}\text { Delivering complex projects } \\
\text { for change }\end{array}$ & $\begin{array}{l}\text { Multi-agenda projects, } \\
\text { manage anxiety, dedication }\end{array}$ & $\begin{array}{l}\text { Delivery of complex projects } \\
\text { for change }\end{array}$ \\
\hline $\begin{array}{l}\text { Few employment } \\
\text { opportunities in Birmingham }\end{array}$ & $\begin{array}{l}\text { Grow the 'green economy' } \\
\text { through these projects }\end{array}$ & Creation of local jobs. \\
\hline
\end{tabular}

